\title{
Comparative analysis of Russian and industrialized countries performance on Energy and Fuels, WoS, 2008-2017
}

\author{
Valentina Markusova, et al. [full author details at the end of the article]
}

Received: 14 November 2019 / Published online: 6 May 2020

(c) Akadémiai Kiadó, Budapest, Hungary 2020

\begin{abstract}
The selection of basic research priorities plays an important role in efficient science policy. After the economic crisis in 2008 many countries turned its attention to R\&D of energy resources. Effective development of R\&D could contribute to efficiency of oil and gas processing and improve Russian prosperity. The goal of our study is to examine trends in Russian research performance (RP) and compare them with other leading industrialized countries. More detailed analysis was focused on tracing evolution in the research area (by WoS classification) as Energy\&Fuel $(E \& F)$, which is invaluable for the Russian economy. Sources of data were Science Citation Index-Expanded (SCI-E) that is the part of Web of Science (WoS), analytical tool InCites and the national database Russian Science Citation Index-Clarivate. World dataset demonstrated the growth rate in total research performance (RP) by $140 \%$ (2,006,082 records) in 2017 compared to 2008 (1,416,233 records). Russian RP growth rate was the same as in world dataset in 2008-2017. Our analysis revealed that two of each RA Science Technology and Other Topics, and Energy \& Fuels $(E \& F)$ demonstrated striking growth rate (in three-fold) comparing with growth rate $140 \%$ in the world dataset during 2008-2017. Total amount of Russian RP on $E \& F$ consisted of 4237 records indexed in SCI-E and 6300 records indexed in RSCI-C for 10 years. During the last 10 years, Russia significantly improved various citations indicators of RP on $E \& F$. The share of publications in top $1 \%$ and top $10 \%$ journals increased. Russian RP growth rate on $E \& F$ was about $200 \%$. Despite the growth its impact is low compared to leading industrial countries. A significant disparity was revealed in RP distribution by leading organizations in SCI-E and RSCI-C. Powerful Russian oil and gas companies are practically absent among organizations indexed in SCI-E. Contrarily, the national Russian database RSCI-C revealed a network of regional branches of the famous private oil company named "Lukoil". Russian international collaboration (IC) on $E \& F$ is significantly less (about 8-10\%) than in total Russian RP. The negative factor is low number of IC on $E \& F$ with each of traditional Russian partners as Germany and USA. Value of Jaccard index of almost all countries collaborating with Russia (besides Kazakhstan's 0.46) is no higher than 0.2. This indicates significant difference in direction of research. Our data could be useful as a source for effective decision-making.
\end{abstract}

Keywords Bibliometric · Energy and Fuels · Indicators · InCites · WoS

This paper is dedicated to the memory of Judit Bar-Ilan (1958-2019), an outstanding scholar and an inimitable friend and colleague. 


\section{Introduction}

Russian science policy and its impact on bibliometric performance was the object of a few studies published recently (Abbott and Schiermeier 2014; Radocevich and Yoruk 2014; Ivanov et al. 2016; Karaulova et al. 2016; Turko et al. 2016, Gilyarevskii et al. 2019). On December 1, 2018 the President of Russian Federation signed Decree N 204 (http://static.kremlin.ru/media/acts/files/0001201805070038.pdf) that set up a prestigious goal of entry into the list of the five largest economies of the world. This goal could be achieved "with consolidation and unity actions of strategic planning, ensuring the development of socio-economic, scientific, and technological fields of activity" (Mindeli et al. 2019). The selection of basic research priorities plays an important role in efficient science policy. Russia, Saudi Arabia, and USA are the top three crude oil producers. Russia is the second biggest oil exporter in the world, making its economy vastly dependent on the global oil market. Official statistics suggest that Russia's oil and gas industry accounts for only a quarter of the country's GDP. However, when other factors are taken into account, the economy is seen to be much more heavily dependent on hydrocarbons (Movchan and Koshkin 2017) https://carnegieendowment.org/exper ts/1057. According to an estimation by Tekingunduz (2018) oil and gas exports constitute $40 \%$ of the total federal budget revenue of Russia https://www.trtworld.com/europe/ how-oil-prices-impact-russia-s-economy-22067.

Russia sells mainly crude oil due to old equipment and the high cost of processing. After the economic crisis in 2008 many countries turned its attention to R\&D of energy resources (Gibson and Hazelkorn 2017). According to official announcement the U.S. Department of Energy's (DOE) Office of Science (OS) established the Energy Frontier Research Center (EFRC) program to accelerate the scientific breakthroughs in 2009. Centers were selected in open competition based on peer review. The OS funded the first round of 46 Energy Frontiers Research Centers (EFRC) and \$777 millions were allocated https://science.osti.gov/bes/efrc/. The results of the first round indicate that "despite lacking formal mechanisms for coordinating research, EFRCs increase co-authorships among EFRC members, especially new co-authorships. EFRC participants' research quality increase after each EFRC is formed" (Smith et al. 2016). During 2016-2018 the OS allocated \$780 millions to the program. Since the program was established there have been $82 \mathrm{EFRC}$, of which 46 are active now https://science.osti. gov/bes/efrc/History.

Comprehensive bibliometrics analysis on nanoscience conducted by Wang et al. (2019) indicated that "among 20 emerging topics, primarily in the energy and twodimensional material domains that have a great opportunity for development in the coming few years".

The goal of our study is to examine trends in Russian research priorities and compare them with other leading industrialized countries. More detailed analysis was focused on tracing evolution in the research area of Energy\&Fuel $(E \& F)$, which is invaluable for the Russian economy. We track the pattern of international collaboration, domestic collaboration between regions, and with industry. The time frame spans a 10 years period, 2008-2017. 


\section{Methodology}

The main sources of bibliometric statistics were products produced by Clarivate Analytics: Science Citation Index-Expanded (SCI-E), Journal Citation Reports (JCR) and the analytical tool InCites. SCI-E was selected due to significant difference in Russian Research Performance (RP) between SCI-E (about 33,000 records), Social Science Citation Index (about 1200 records) and Art \& Humanities Citation Index (300 records) yearly. Our analysis was focused on records indexed only in SCI-E. We want to emphasize that SCI-E processes one hundred sixty-one titles of Russian journals, SSCI-ix titles and Art \& Humanities Citation Index only four titles annually. To get additional information on Russian RP we collected data from the national database named Russian Science Citation Index (RSCI)-C. The acronym RSCI-C indicates the Russian Science Citation Index at Clarivate, a database with Russian literature created by E.Library together with Clarivate Analytics https://elibrary.ru/project_risc.asp. This index is similar to Clarivate's Korean, Chinese and Latino Citation Index. This group of four indexes is included in the Web of Science (WoS) Platform, but their sources are not processed for the WoS or Current Contents (Moed et al. 2018). Index covers 628 journals' title since 2005-present https://clarivate.libguides.com/webofsciencepla tform/rsci.

We used classification by Research Area (RA) to trace the changes in scientific disciplines in world dataset and Russian dataset. There are $152 \mathrm{RA}$ in WoS. Option Research Analysis was used to rank countries by RA. Time period 2008-2017. The search was performed on April 23, 2019. Russian records were exported with WoS option «Export Records to File» (Full Record and Cited Reference) during 2008-2017. More than 337,000 Russian records were downloaded from SCI-E and uploaded in the special database on the platform MS SQL.

More detailed analysis was focused on tracing evolution in the research area as Energy\&Fuel $(E \& F)$. Total amount of Russian RP on $E \& F$ consisted of 4237 records indexed in SCI-E and 6300 records indexed in RSCI-C for 10 years. Identification of international and national collaboration was evaluated by number of joint publications. Special attention will be given to domestic collaboration (DC) between regions. We define DC as collaboration between institutions from the same country. We operationalize this by counting the number of publications in which more than one author affiliation is from the same country. To compare Russian impact with other industrialized countries on $E \& F$, statistics on various citations' indicators was derived from InCites on May 3-5, 2019. These data were selected for two five-years periods 2008-2012 and 2013-2017 to avoid annual fluctuation.

Compound annual growth rates CAGR (Moed et al. 2018) and Jaccard index (https://en.wikipedia.org/wiki/Jaccard_index) were calculated for two time periods 2008-2017 and 2013-2017. Prof. Glänzel (2003) introduced the usage of Jaccard index (JI) in bibliometrics. This index was also used for a comparison of universities' publications strategy by Pislyakov et al. (2019). We used Pislyakov's methodology to calculate JI. In our case, the index was calculated on the basis of country publications similarity in journals. When the value of JI is equal to one, it indicates strong similarity in research field between Russia and collaborating country. Statistics on RP was derived from InCites on 10.09.2019. 


\section{Results}

World dataset demonstrated the growth rate in total RP by $140 \%(2,006,082$ records $)$ in 2017 compared to 2008 (1,416,233 records). However, the growth rate was about 125\% during 2008-2013 and slowed to 110\% during 2013-2017. In contrast, Russian RP growth rate was approximately the same as in world dataset in 2008-2017. It was observed that the growth rate of Russian RP was one hundred ten percent in 2008-2013 and one hundred twenty-five percent 2013-2017. It is doubtless that the government's investment policy toward stimulating basic research at universities could be attributed to this impact. Our data is consistent with results of the study performed by Moed (Scientometrics, 2018). The investigation shows that industrialized countries gradually diminished their share of RP as the developing world is catching up in knowledge distribution. Among 50 countries ranked by RP significant growth, the highest growth rate over a 10-year period was demonstrated by China (3.1 fold), Egypt (2.9 fold), Iran (2.92 fold) and Chile (2.3 fold). As in 2008, Russia continues to occupy the same 15 th rank by RP in 2017. These data are presented in Table 7 in the "Appendix".

We investigated changes in priorities between one hundred RA in the world dataset. There was little change between RA that occupied first four ranks: Chemistry, Engineering, Physics and Material Science. Despite the growth in absolute numbers in RA on life sciences, and biomedicine, there were only two that demonstrated growth rate significantly higher than in total dataset. They are RA Oncology (6th rank in 2017, compared to 8th rank in 2008) and RA Research Experimental Medicine (17th rank in 2017, compared with 31th rank in 2008): each of which had an increase of RP two-fold.

A striking growth rate (threefold) was observed in both of RA Science Technology and Other Topics (5th rank in 2017 compared to 14th rank in 2008) and RA Energy and Fuels (18th rank in 2017 compared to 48th rank in 2008). Absolute number of publications on Energy and Fuel $(E \& F)$ in world dataset was 13,390 records and 39,100 records in 2008 and 2017. The growth of RP on RA Energy and Fuels is presented at Fig. 1.

The list of twenty-five leading RA in 2008 and 2017 is displayed in Table 1. The countries were ranked by RP in 2008.

To trace changes in RP between leading organizations on $E \& F$ we compared the list of top fifty organizations in 2008 and 2017. As in 2008 (303 records), The Chinese Academy of Sciences (CAS) topped the list in 2017 (1770 records). Our data clearly showed that Chinese universities play a growing role in this research area. The US

Fig. 1 World trends of research productivity on Energy\&Fuels, WoS (SCI-E)

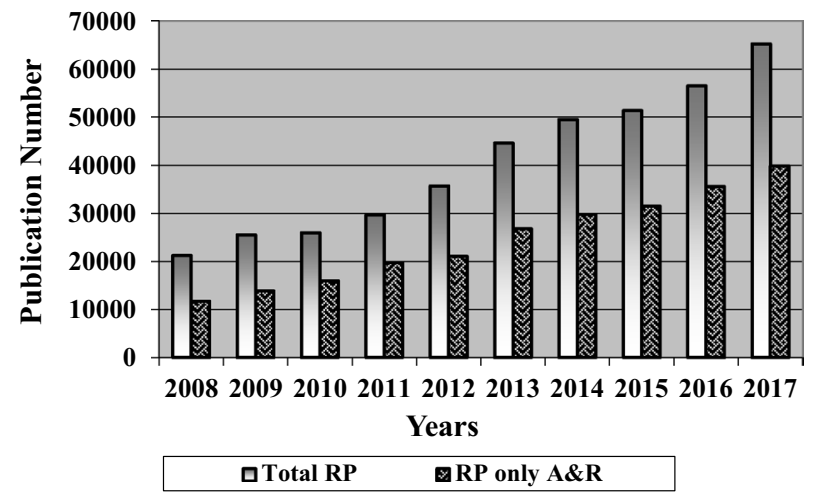


Table 1 The list of twenty-five leading research areas, SCI-E, 2008 and 2017

\begin{tabular}{|c|c|c|c|c|c|c|}
\hline \multirow[t]{2}{*}{ Research areas } & \multicolumn{2}{|l|}{ Rank } & \multicolumn{2}{|c|}{$\begin{array}{l}\text { Number of } \\
\text { records SCI-E }\end{array}$} & \multirow{2}{*}{$\begin{array}{l}\% \text { of } 1,416,233 \\
2008\end{array}$} & \multirow{2}{*}{$\begin{array}{l}\% \text { of } 2,006,082 \\
2017\end{array}$} \\
\hline & 2008 & 2017 & 2008 & 2017 & & \\
\hline Chemistry & 1 & 1 & 154,005 & 222,458 & 10.87 & 11.09 \\
\hline Physics & 2 & 3 & 125,890 & 142,853 & 8.89 & 7.12 \\
\hline Engineering & 3 & 2 & 123,034 & 201,804 & 8.69 & 10.06 \\
\hline Biochemistry Molecular Biology & 4 & 8 & 82,119 & 83,297 & 5.80 & 4.15 \\
\hline Materials Science & 5 & 4 & 81,833 & 142,209 & 5.78 & 7.89 \\
\hline Neurosciences Neurology & 6 & 7 & 79,013 & 99,176 & 5.58 & 4.94 \\
\hline Pharmacology Pharmacy & 7 & 11 & 54,072 & 64,894 & 3.82 & 3.23 \\
\hline Oncology & 8 & 6 & 53,335 & 99,201 & 3.77 & 4.94 \\
\hline Cardiovascular System Cardiology & 9 & 12 & 51,544 & 63,449 & 3.64 & 3.16 \\
\hline Mathematics & 10 & 13 & 47,842 & 61,603 & 3.38 & 3.07 \\
\hline General Internal Medicine & 11 & 10 & 44,517 & 67,345 & 3.15 & 3.36 \\
\hline Surgery & 12 & 14 & 44,433 & 60,521 & 3.13 & 3.02 \\
\hline Environmental Sciences Ecology & 13 & 9 & 42,864 & 74,969 & 3.03 & 3.74 \\
\hline Cell biology & 14 & 16 & 41,405 & 56,158 & 2.92 & 2.80 \\
\hline Science Technology Other Topics & 15 & 5 & 41,385 & 129,009 & 2.92 & 6.43 \\
\hline Computer Science & 16 & 15 & 34,519 & 58,851 & 2.44 & 2.93 \\
\hline Immunology & 17 & 19 & 33,373 & 39,003 & 2.36 & 1.94 \\
\hline Agriculture & 18 & 21 & 31,314 & 36,697 & 2.21 & 1.83 \\
\hline Endocrinology Metabolism & 19 & 24 & 29,216 & 33,980 & 2.06 & 1.69 \\
\hline Gastroenterology Hepatology & 20 & 22 & 28,470 & 34,323 & 2.01 & 1.71 \\
\hline Biotechnology Applied Microbiology & 21 & 25 & 26,642 & 33,353 & 1.90 & 1.67 \\
\hline Hematology & 22 & 27 & 25,862 & 29,922 & 1.83 & 1.50 \\
\hline $\begin{array}{l}\text { Radiology Nuclear Medicine Medical } \\
\text { Imaging }\end{array}$ & 23 & 26 & 24,833 & 32,546 & 1.75 & 1.62 \\
\hline $\begin{array}{l}\text { Public Environmental Occupational } \\
\text { Health }\end{array}$ & 24 & 20 & 22,780 & 37,584 & 1.61 & 1.87 \\
\hline Psychiatry & 25 & 28 & 22,145 & 29,794 & 1.56 & 1.48 \\
\hline Research Experimental Medicine & 29 & 17 & 20,629 & 40,015 & 1.46 & 1.99 \\
\hline Energy Fuels & 48 & 18 & 13,590 & 39,100 & 0.96 & 1.95 \\
\hline Respiratory System & 59 & 23 & 10,316 & 34,043 & 0.73 & 1.70 \\
\hline
\end{tabular}

Research areas were ranked by number of records in 2008

Department of Energy (DOE) ranked 3rd (209 records) and 2nd (1018 records) in 2008 and 2017 respectively. The Russian Academy of Sciences (RAS) occupied 5th rank (164 records) in 2008 and diminished its position to 20th rank (317 records) in 2017. Its growth rate was significantly less (1.8 fold) compared to a growth rate of CAS (5.8 fold) and DOE (5.0 fold), Helmholtz Foundation (6.5 fold) and dozens of other organizations.

Total Russian RP consisted of 29,000 records in 2008 and 41,000 records in 2017. Russian science demonstrated the strong tendency toward "hard sciences" during all studied period. Table 2 contains data on Russian RA in 2008 and 2017. 
Table 2 Twenty-five leading research areas in Russia, SCI-E, 2008 and 2017

\begin{tabular}{|c|c|c|c|c|c|c|}
\hline \multirow[t]{2}{*}{ Research areas } & \multicolumn{2}{|l|}{ Ranks } & \multicolumn{2}{|c|}{$\begin{array}{l}\text { Number of } \\
\text { records }\end{array}$} & \multirow{2}{*}{$\begin{array}{l}\% \text { of } 29,682 \\
2008\end{array}$} & \multirow{2}{*}{$\begin{array}{l}\% \text { of } 41,223 \\
2017\end{array}$} \\
\hline & 2008 & 2017 & 2008 & 2017 & & \\
\hline Physics & 1 & 1 & 8172 & 9889 & 27.53 & 23.99 \\
\hline Chemistry & 2 & 2 & 5423 & 7336 & 18.27 & 17.80 \\
\hline Materials Science & 3 & 3 & 2171 & 3866 & 7.31 & 9.38 \\
\hline Mathematics & 4 & 5 & 1931 & 2475 & 6.51 & 6.00 \\
\hline Engineering & 5 & 4 & 1781 & 2972 & 6.00 & 7.21 \\
\hline Biochemistry Molecular Biology & 6 & 6 & 1344 & 1919 & 4.53 & 4.66 \\
\hline Astronomy Astrophysics & 7 & 7 & 1334 & 1650 & 4.49 & 4.00 \\
\hline Geology & 8 & 10 & 1062 & 1240 & 3.58 & 3.01 \\
\hline Optics & 9 & 9 & 1014 & 1583 & 3.42 & 3.84 \\
\hline Neurosciences Neurology & 10 & 14 & 863 & 926 & 2.91 & 2.25 \\
\hline Mechanics & 11 & 11 & 758 & 1084 & 2.55 & 2.63 \\
\hline Instruments Instrumentation & 12 & 13 & 737 & 1007 & 2.48 & 2.44 \\
\hline Geochemistry Geophysics & 13 & 16 & 675 & 750 & 2.27 & 1.82 \\
\hline Metallurgy Metallurgical Engineering & 14 & 15 & 668 & 923 & 2.25 & 2.24 \\
\hline Cardiovascular System Cardiology & 15 & 12 & 624 & 1019 & 2.10 & 2.47 \\
\hline Science Technology Other Topics & 16 & 8 & 537 & 1630 & 1.81 & 3.95 \\
\hline Environmental Sciences Ecology & 17 & 17 & 481 & 748 & 1.62 & 1.82 \\
\hline Research Experimental Medicine & 18 & 20 & 463 & 594 & 1.56 & 1.44 \\
\hline Physiology & 19 & 48 & 447 & 260 & 1.51 & 0.63 \\
\hline Meteorology Atmospheric Sciences & 20 & 30 & 440 & 477 & 1.48 & 1.16 \\
\hline Nuclear Science Technology & 21 & 25 & 439 & 544 & 1.48 & 1.32 \\
\hline Spectroscopy & 22 & 22 & 378 & 575 & 1.27 & 1.40 \\
\hline Microbiology & 23 & 33 & 370 & 431 & 1.25 & 1.05 \\
\hline Thermodynamics & 24 & 26 & 358 & 541 & 1.21 & 1.31 \\
\hline Biophysics & 25 & 31 & 352 & 471 & 1.19 & 1.14 \\
\hline Pharmacology Pharmacy & 28 & 18 & 338 & 691 & 1.14 & 1.68 \\
\hline Energy Fuels & 32 & 19 & 307 & 664 & 1.03 & 1.61 \\
\hline Zoology & 30 & 21 & 329 & 592 & 1.11 & 1.44 \\
\hline Oncology & 34 & 23 & 268 & 572 & 0.90 & 1.39 \\
\hline Computer Science & 33 & 24 & 306 & 551 & 1.03 & 1.34 \\
\hline
\end{tabular}

Seven top RA Physics, Chemistry, Biochemistry and Molecular Biology, Engineering, Mathematics, Astronomy and Astrophysics continue to hold strong positions but their share diminished 1-4\% in total Russian RP in 2017 compared to figures for 2008. RA Science Technology and Other Topics improved its rank from 16th up to 8th in 2017 (share from $1.8 \%$ up to 3.9\%). RA Optics holds its 9th rank in Russian RP and 5th in the world dataset. A positive trend was witnessed in the appearance of more RA related to life sciences and biomedicine in total Russian RP in 2017 compared to 2008: 76 RA compared to 67 correspondently. But their contribution is still significantly less than "hard sciences".

RA $E \& F$ improved its position moving from 32-nd ranks up to 19th rank in 2017 (share from 1.0 up to 1.6\%). Total Russian RP on $E \& F$ consisted of 4237 publications 
Fig. 2 Trends in Russian publications on RA $E \& F$, SCI-E and RSCI-C, 2008-2017

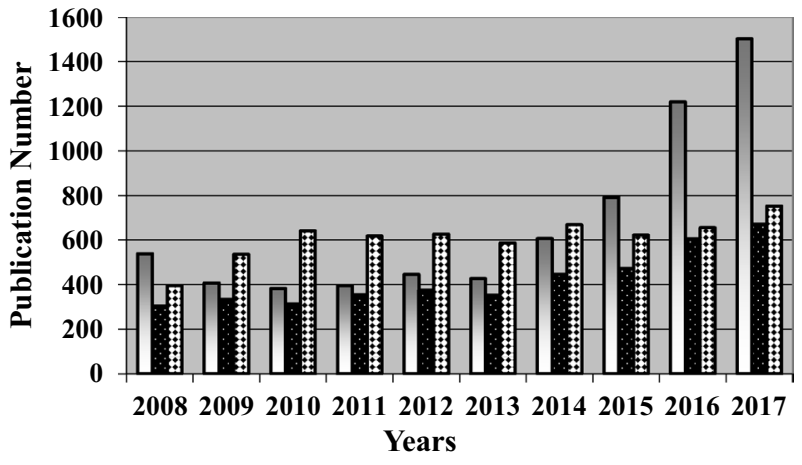

口Total RP, WoS RP only A\&R, WoS 田Total RP, RSCI-C

indexed in SCI-E and 6300 indexed in RSCI-C for 2008-2017 (Fig. 2). These publications were focused on following disciplinary subject categories: Physics Applied, Oil processing, Efficiency of oil and gas transportation, Engineering Petroleum Chemical.

A significant disparity was revealed in RP on $E \& F$ distribution by organizations in SCI-E and RSCI-C. There are two leading sectors of basic research in Russia: the RAS and universities (or the Higher Education Sector). RAS occupied the leading position in the entire studied period, but its share was diminished from 50.1 to $41.2 \%$ in 2008 and 2017 correspondently in SCI-E. Remarkably $80 \%$ of RAS articles on $E \& F$ were published in Q1 and Q2 journals (JCR, 2017). This is a great achievement for RAS publications because the share of publications in Q1 and Q2 journals was about 42\% in total Russian RP (JCR, 2017). We need to emphasize here the policy of the Ministry of Science and Education (MSE) to allocate additional funds for organizations publishing in Q1 and Q2 journals http://static.government.ru/media/files/UraNEEbOnbjocoMLPOnnJZx4OT20Siei.pdf. Contribution of various National Research Universities (there are 35 universities awarded by this title) and industrial universities showed a noticeable growth since 2013. Various citations indicators characterizing impact of Russian publications are presented in Table 3.

Russia improved the value of category-normalized citation impact (CNCI) and percentage of documents published in top 1\% in 2013-2017 compared to 2008-2012 (see Table 4). But its share of publications (about 18.5\%) in Q1 journals on $E \& F$ is three folds lower than in other countries and significantly lower (18.5\%) than in total Russian RP (26.5\%) in 2013-2017 by InCites.

Collaboration with industry was never a strong point of Russian science. However, it was a little bit higher (1.4\%) than in total Russian RP (0.89\%). Norway demonstrates strongest links with the industry (about 21.0\%, rank 29th), followed by France (7.7\%) and Switzerland (6.0\%) in 2013-2017 (see Table 3).

Growth of international collaboration (IC) is one of the features of globalization. Our analysis shows that the share of IC on $E \& F$ was between 22.0 and $24.7 \%$, which is lower comparing with IC share (30-32\%) in total Russian RP in last 10 years. The list of collaborative countries expanded during the ten-year period, but the pattern of collaboration was sporadic. We have to emphasize that during last 20 years USA, Germany have been leading partners in IC, the share of joint publications of each of them was between 9 and $10 \%$ in total Russian RP. However, analysis of Russian IC on $E \& F$ indicated that absolute number IC publications with five largest economies (USA, Germany, France, Japan and China) was low as in 2008 (five-seven joint publications) and 


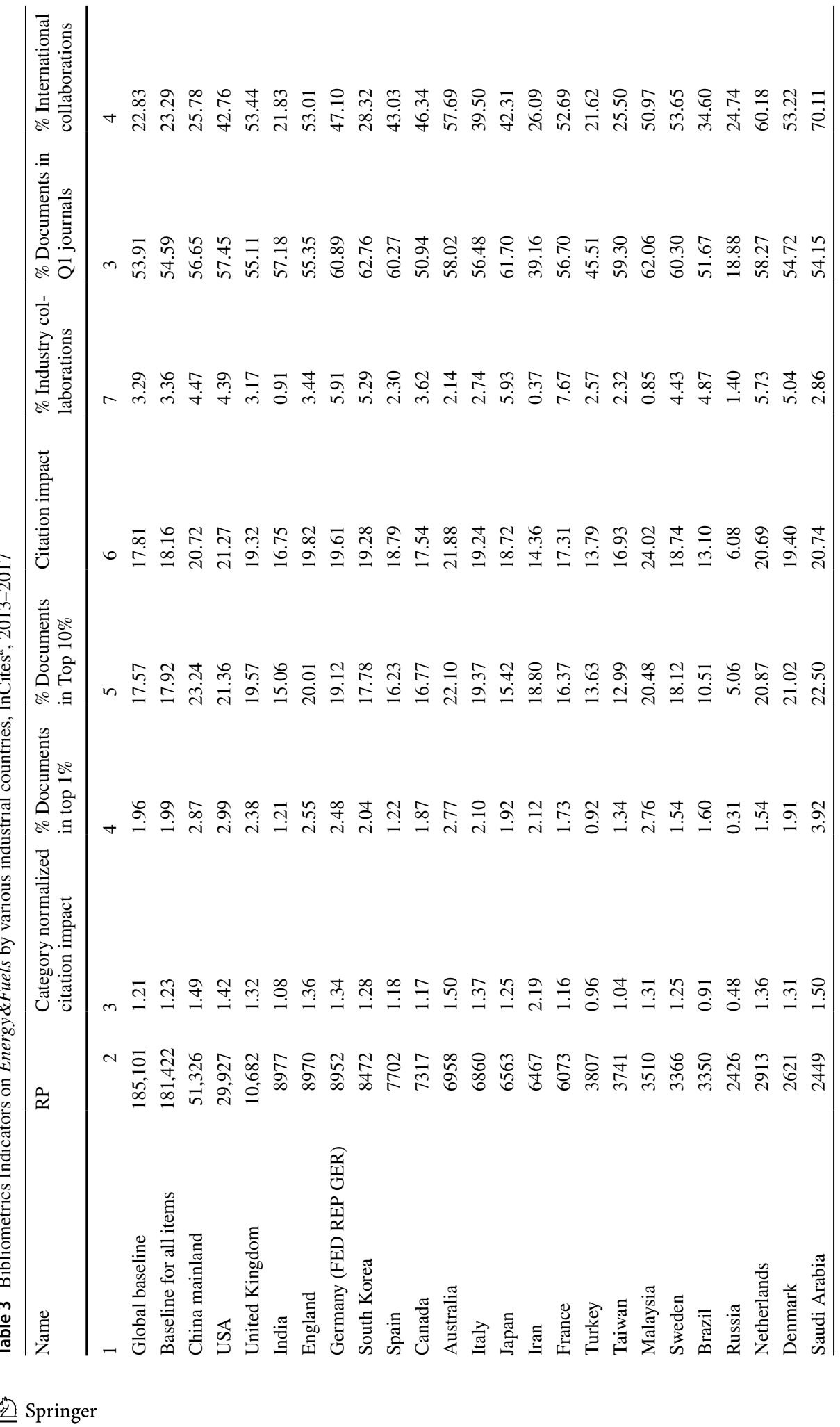




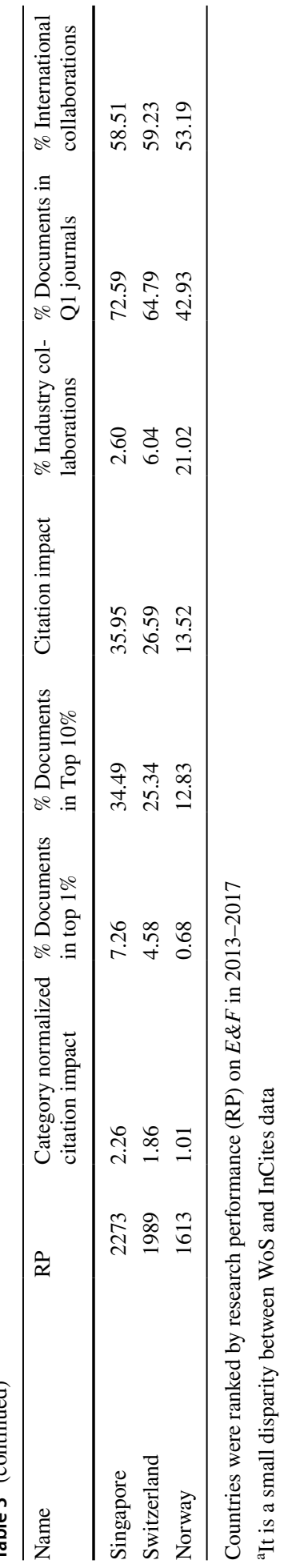




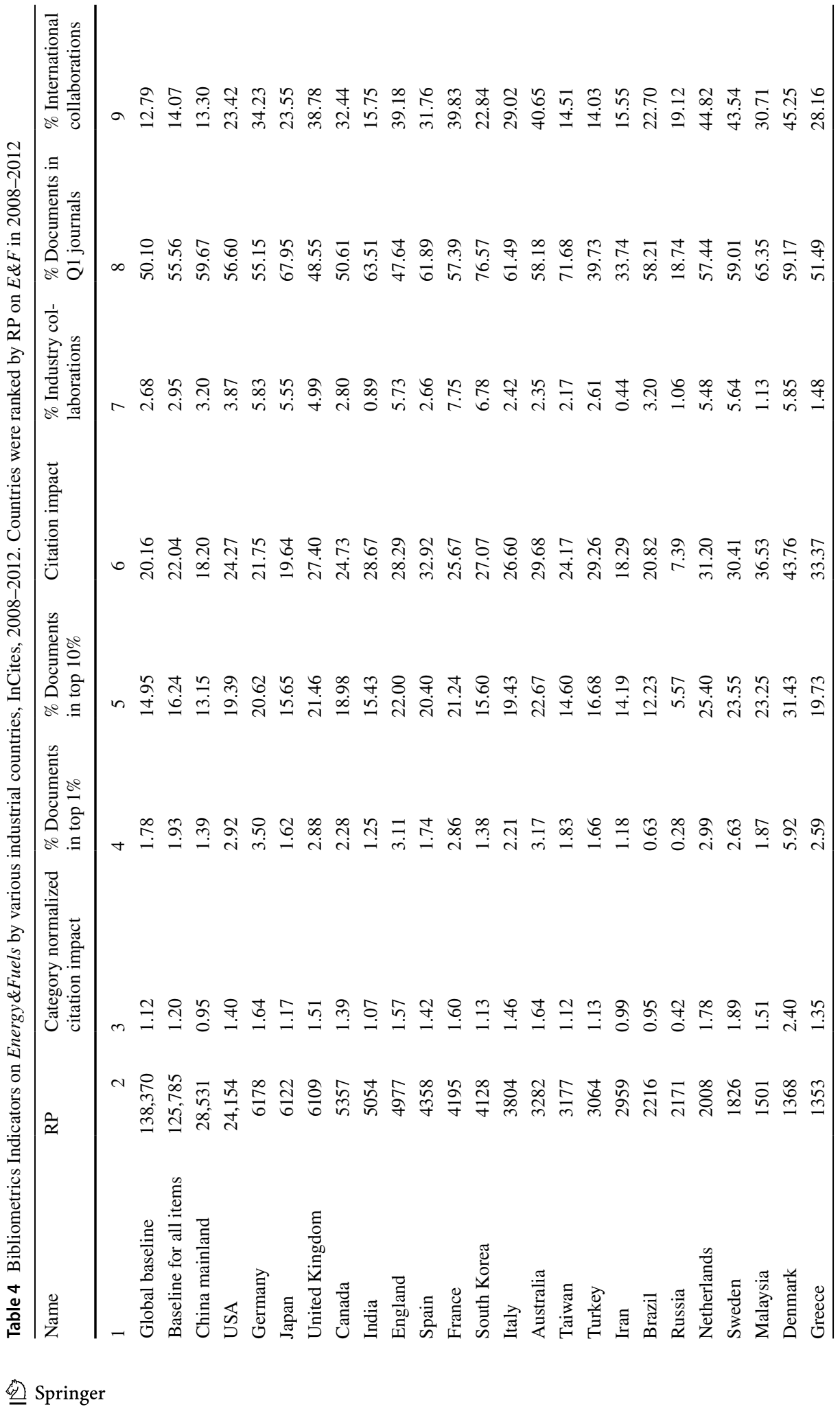




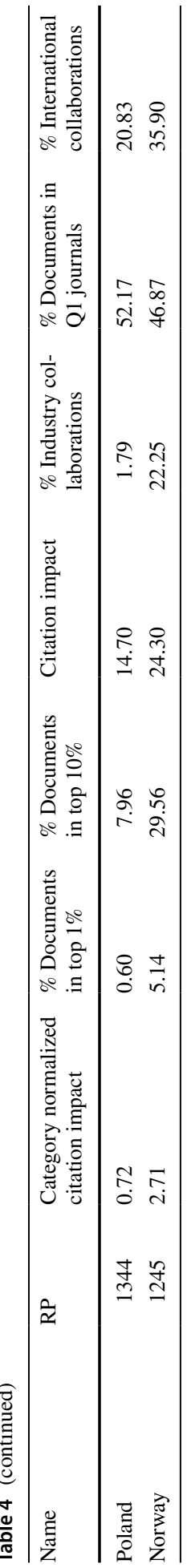




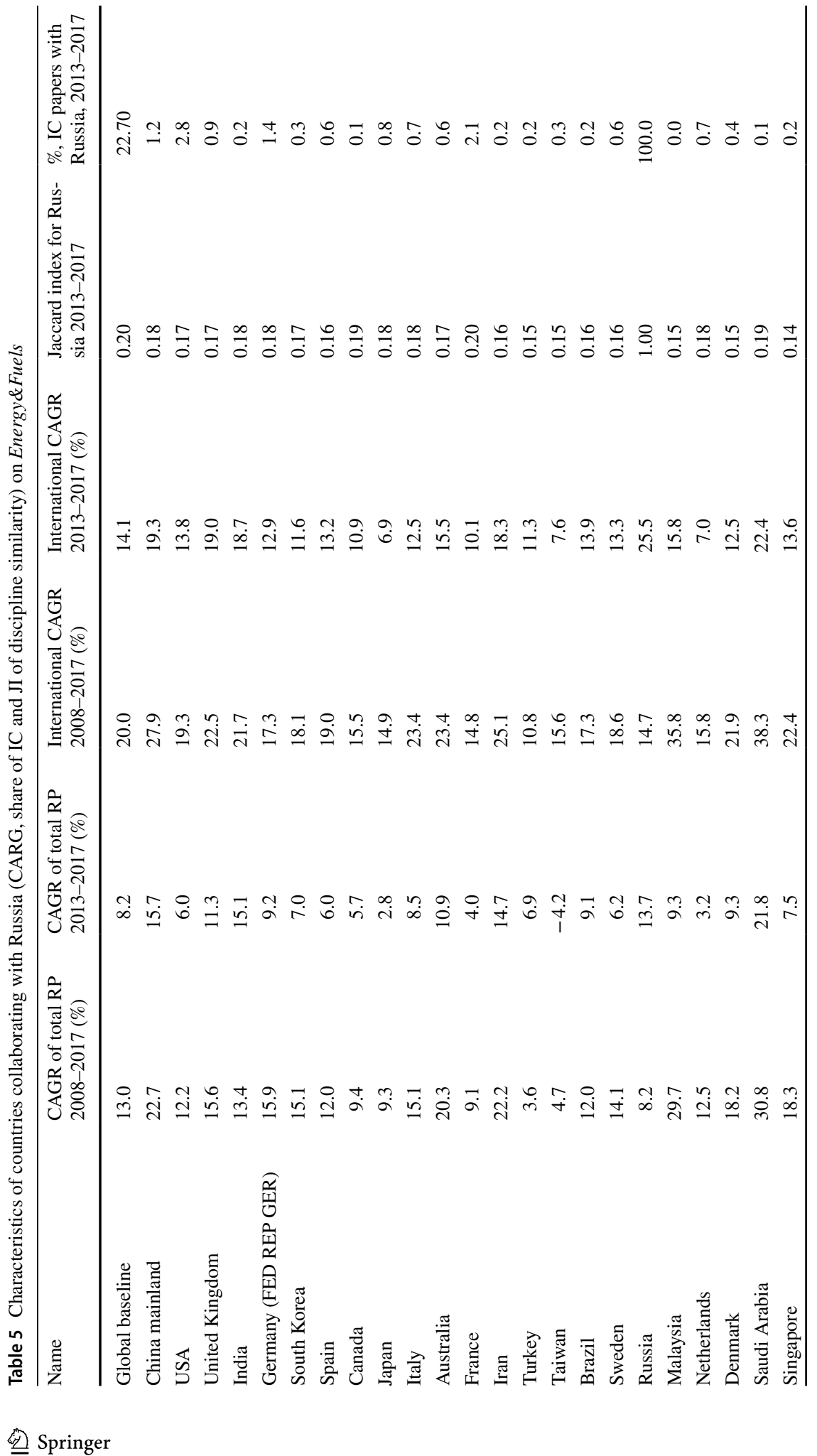




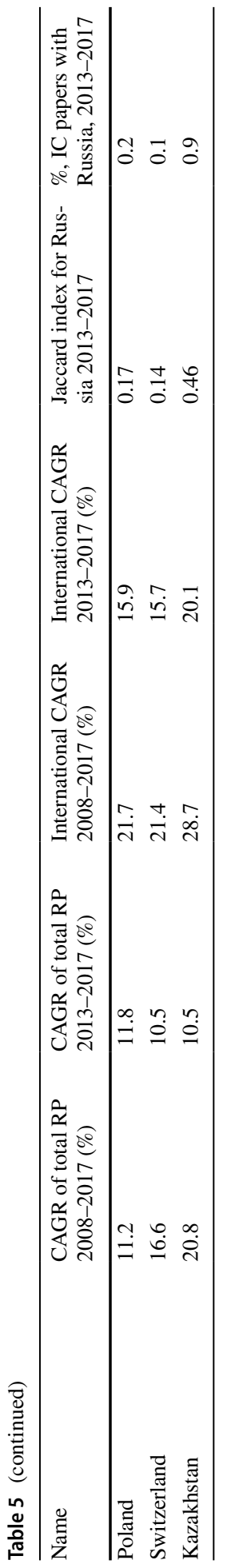


in 2017 (ten-fifteen joint publications) respectively. We think that sociological survey could shed a light on this phenomenon. Characteristics of countries collaborating with Russia (CARG, share of IC and JI of discipline similarity) on $E \& F$ are presented in Table 5 .

Taiwan is one country that demonstrated a negative CARG on $E \& F$ during 2013-2017 comparing with 2008-2017. As we noticed above, share of Russian IC papers on $E \& F$ with USA and Germany are significantly lower $(2.8 \%$ and $1.4 \%$ correspondently) compared with each country share in total Russian RP (each 9-10\% annually). However, both countries share on E\&F are significantly higher compared with other collaborative countries. Nevertheless, we want to emphasize that Russia has lowest share of IC with countries (Saudi Arabia, India, Iran, Malaysia and Switzerland) whose CARG higher than CARG for 2013-2017 in global dataset. Value of Jaccard index of almost all countries collaborating with Russia (besides Kazakhstan's 0.46) is no higher than 0.2. This indicates significant difference in direction of research. Possibly, strength of cooperation is a due to a difference in priorities of collaborative research.

The domestic collaboration (DC) stimulates knowledge transfer into industry. However, DC share was lower (between 15 and 18\%) compared to total Russian RP (24\%) (Mindeli et al. 2016). Collaboration among organizations was mainly bilateral and stable during 2008-2017. Number of organizations per article is an average 2.7. It is similar as in total Russian RP.

An upgraded map of domestic collaboration taking place in 2008-2017 by different economic regions was designed. The strength of collaboration was evaluated by looking at the number of researchers involved in collaborative efforts. The list of regions involved in DC increased from thirty-one in 2008 up to forty-three in 2017. In total, sixty-three regions were involved in DC during 2008-2017. There were selected nine regions leading by number of joint publications on RA Energy\&Fuels. The matrix of collaboration is presented at Table 6.

Moscow is well-known science city and has strong ties with various regions. Its share of DC on $E \& F$ was about $11 \%$. A positive sign is a growing collaboration within the regions: share of DC in Kemerovo and Sverdlovsk regions (Ekaterinburg is a part of this region) were higher than in Moscow (11\%): $23 \%$ and $17 \%$ respectively.

The total amount of Russian RP on $E \& F$ consisted 6300 records indexed in RSCI-C. The trends in RP $E \& F$ are displayed at Fig. 2. The contribution by universities sector was dominant (about 65.3\%) among organizations indexed by RSCI-C in 2017. The leading organization was the I.V.Gubkin State University on Oil and Gas" (share 4.8\%). The share of the M.V.Lomonosov Moscow State University (MSU) was low (about $1 \%$ ) compared to its second place by RP (4.5\%) among Russian organizations on $E \& F$ indexed in SCI-E. We assume that researchers from RAS organizations as from MSU preferred to be published in journals indexed only in SCI-E. This has contributed partly to the MES policy to give more score to articles indexed in SCI-E. The citation score of $\mathrm{RP}$ on $E \& F$ was very low in RSCI-C.

The influence of industrial agencies is noticeable in RSCI-C. It revealed a network of regional branches of the famous private oil company named "Lukoil". These branches are located in regions where there are oil exploration sites or processing plants. RP on 


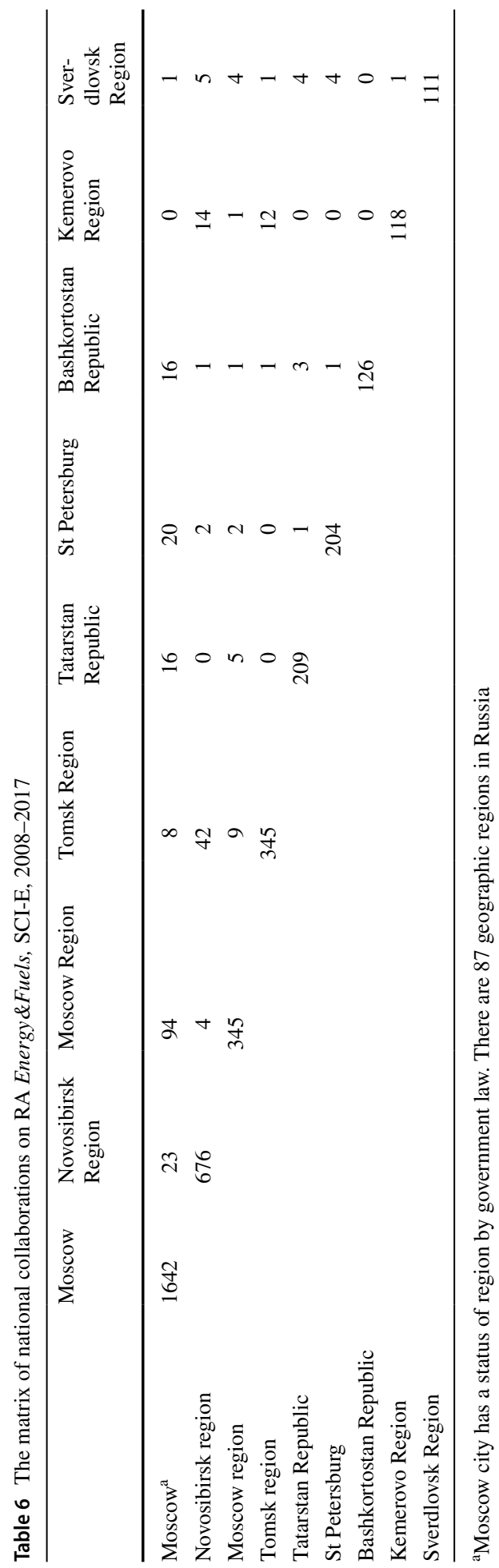


$E \& F$ was disseminated by eleven Russian journals annually indexed in RSCI. Eight of these journals are translated into English, three others contain content, summary and references in English. A list of these journals included in Table 8 in the "Appendix" (Table 2).

\section{Conclusions}

Our analysis of research performance (RP) revealed that two Research Areas (by Web of Science classification) Science Technology and Other Topics and Energy \& Fuels $(E \& F)$ demonstrated striking growth rate (in threefold) comparing with growth rate $140 \%$ in the world dataset during 10 years period 2008-2017. During the last 10 years, Russia improved various citations indicators of RP on $(E \& F)$. The share of publications in top $1 \%$ and top $10 \%$ journals increased. Russian RP growth rate was about $200 \%$. Despite the growth its impact is low compared to leading industrial countries. Russian international collaboration on $E \& F$ is less (about $8 \%$ ) than in total Russian RP. Value of Jaccard index of almost all countries collaborating with Russia (besides Kazakhstan's 0.46 ) is no higher than 0.2 . This indicates significant difference in direction of research. Possibly, strength of cooperation is a due to a difference in priorities of collaborative research. A significant disparity was revealed in RP on $E \& F$ distribution by leading organizations in SCI-E and RSCI-C. Russian international collaboration on $E \& F$ is less (about 8\%) than in total Russian RP.

Powerful Russian oil and gas companies are practically absent among organizations indexed in SCI-E. Contrarily, the national Russian database RSCI-C revealed a network of regional branches of the famous private oil company named "Lukoil". However, these publications are indexed in less known journals. Our data could be useful as a source for effective decision-making.

Acknowledgements Authors express the gratitude to the Russian Foundation for Basic Research for financial support (Grants 17-02-00157 and 17-02-00078) and to Clarivate Analytics for the opportunity to use the data.

Author contributions MA: data collection (InCites, SciVal), analysis, manuscript draft discussion, editing. AL: data collection (WoS), analysis, manuscript draft discussion, editing. VM: acquired funding, conception, analysis, data collection (InCites), first draft of manuscript, editing. LM: conception analysis, acquired funding, manuscript draft discussion, editing. All authors read and approved the manuscript.

\section{Appendix}

See Tables 7 and 8. 
Table 7 Leading countries by research performance, SCI-E, 2008 and 2017

\begin{tabular}{|c|c|c|c|c|c|c|}
\hline \multirow[t]{2}{*}{ Countries/regions } & \multicolumn{2}{|l|}{ Rank } & \multicolumn{2}{|l|}{ Records } & \multirow{2}{*}{$\begin{array}{l}\% \text { of } 1,416,233 \\
2008\end{array}$} & \multirow{2}{*}{$\begin{array}{l}\% \text { of } 2,006,082 \\
2017\end{array}$} \\
\hline & 2008 & 2017 & 2008 & 2017 & & \\
\hline USA & 1 & 1 & 413,083 & 542,756 & 29.17 & 27.06 \\
\hline People's Republic of China & 2 & 2 & 115,138 & 364,168 & 8.13 & 18.15 \\
\hline Germany & 3 & 3 & 101,569 & 132,077 & 7.17 & 6.58 \\
\hline Japan & 4 & 5 & 91,322 & 99,759 & 6.45 & 4.97 \\
\hline England & 5 & 4 & 90,630 & 131,471 & 6.40 & 6.55 \\
\hline France & 6 & 6 & 72,048 & 90,269 & 5.09 & 4.50 \\
\hline Italy & 7 & 7 & 61,907 & 87,000 & 4.37 & 4.34 \\
\hline Canada & 8 & 8 & 60,547 & 82,746 & 4.28 & 4.13 \\
\hline Spain & 9 & 11 & 46,415 & 70,474 & 3.28 & 3.51 \\
\hline India & 10 & 9 & 42,635 & 76,982 & 3.01 & 3.84 \\
\hline South Korea & 11 & 12 & 39,116 & 67,051 & 2.76 & 3.34 \\
\hline Australia & 12 & 10 & 39,030 & 74,783 & 2.76 & 3.73 \\
\hline Netherlands & 13 & 14 & 32,862 & 48,008 & 2.32 & 2.39 \\
\hline Brazil & 14 & 13 & 32,692 & 54,670 & 2.31 & 2.73 \\
\hline Russia & 15 & 15 & 29,682 & 41,223 & 2.10 & 2.06 \\
\hline Switzerland & 16 & 16 & 24,829 & 40,284 & 1.75 & 2.01 \\
\hline Taiwan & 17 & 21 & 23,587 & 27,676 & 1.67 & 1.38 \\
\hline Turkey & 18 & 18 & 22,265 & 33,411 & 1.57 & 1.67 \\
\hline Sweden & 19 & 19 & 21,334 & 32,630 & 1.51 & 1.63 \\
\hline Poland & 20 & 20 & 21,067 & 31,643 & 1.49 & 1.58 \\
\hline Belgium & 21 & 22 & 18,427 & 26,793 & 1.30 & 1.34 \\
\hline Scotland & 22 & 25 & 13,615 & 18,973 & 0.96 & 0.95 \\
\hline Greece & 23 & 36 & 13,491 & 13,478 & 0.95 & 0.67 \\
\hline Austria & 24 & 24 & 13,398 & 20,356 & 0.95 & 1.02 \\
\hline Iran & 25 & 17 & 13,183 & 38,458 & 0.93 & 1.92 \\
\hline Denmark & 27 & 23 & 12,574 & 23,244 & 0.89 & 1.16 \\
\hline
\end{tabular}

Countries were ranked by research performance in 2008 


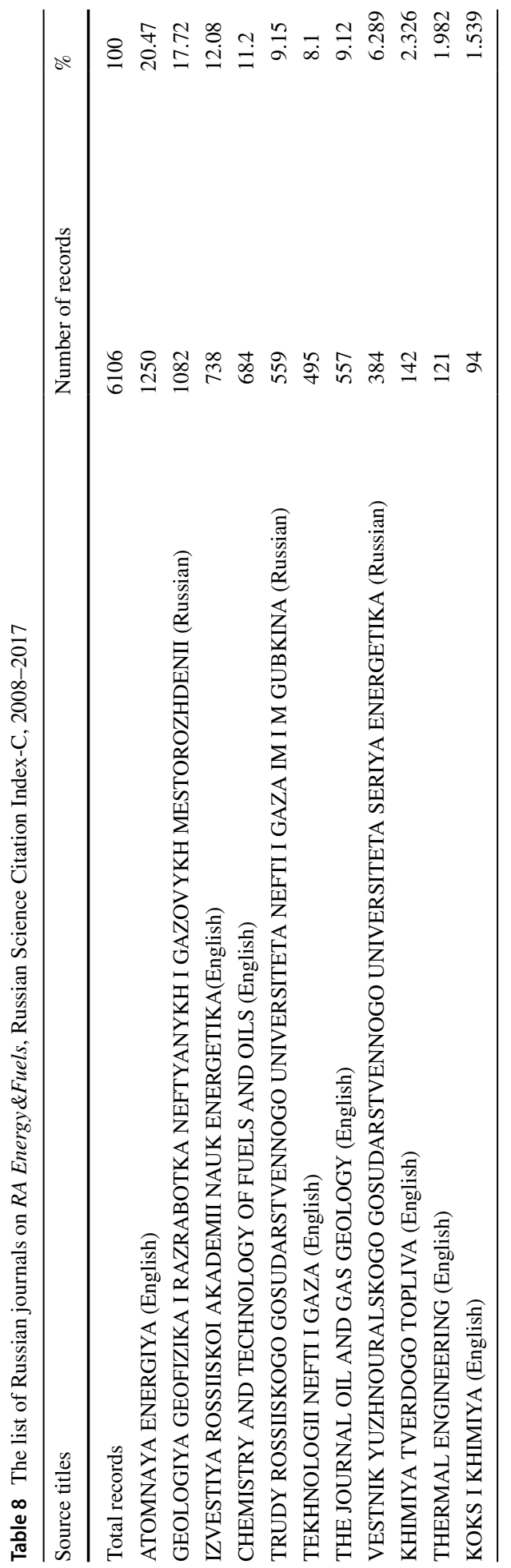




\section{References}

Abbott, A., \& Schiermeier, Q. (2014). Central Europe up-close. Nature, 515, 2-4.

Gibson, A. G., \& Hazelkorn, E. (2017). Arts and humanities research, redefining public benefit, and research prioritization in Ireland. Research Evaluation, 26(3), 199-210.

Gilyarevskii, R., Libkind, A., \& Markusova, V. (2019). Dynamics of Russian publications activity 19932017. Automatic Documentation and Mathematical Linguistics, 53(2), 51-63.

Glänzel, W. (2003). Bibliometrics as a research field: A course on theory and application of bibliometric indicators. Course Handouts, Leuven. Retrieved January 8, 2019, from http://nsdl.niscair.res.in/ jspui/bitstream/123456789/968/1/Bib_Module_KUL.pdf.

Ivanov, V. V., Markusova, V. A., \& Mindeli, L. E. (2016). Government investments and the publishing activity of higher educational institutions: Bibliometric analysis. Herald of the Russian Academy of Sciences, 86(4), 314-321.

Karaulova, M., Abdullah, G., Shackleton, O., \& Shapira, P. (2016). Science system pass-dependencies and their influences: Nanotechnology research in Russia. Scientometrics, 100(3), 365-383. https://doi. org/10.1007/s11192-016-1916-3.

Mindeli, L. E., Ivanov, V. V., Libkind, A. N., \& Markusova, V. A. (2016). Bibliometric approach to national collaboration analysis based on co-authorship: Web of Science, 2006-2013. Scientific and Technical Information, Ser. 1, 8, 14-23.

Mindeli, L. E., Ostapyuk, S. F., \& Fetisov, V. P. (2019). On long-term prediction of fundamental and exploratory research. Economics and Mathematical Methods, 55(1), 56-67.

Moed, H., Markusova, V., \& Akoev, M. (2018). Trends in Russian research output indexed in Scopus and Web of Science. Scientometrics, 118(2), 1153-1180. https://doi.org/10.1007/s11192-018-2769-8.

Movchan, A., \& Koshkin, P. (2017). Russia and the "resource curse": When the Kremlin's policy is counterproductive for the economy. Retrieved May 29, 2019, from https://carnegieendowment.org/publicatio ns/68753

Pislyakov, V., Moskaleva, O., Akoev, M. (2019). Cui Prodest? Reciprocity of collaboration measured by Russian Index of Science Citation. In Proceedings of ISSI 2019-the 17th international conference on scientometrics and informetrics (pp. 185-195). Italy: Sapienza University of Rome.

Radocevich, R., \& Yoruk, L. (2014). Are there global shifts in the world science base? Analyzing the catching up and falling behind of world regions. Scientometrics, 101(3), 1897-1924. https://doi.org/10.1007/ s11192-014-1344-1.

Smith, A., Lai, S. Y., Bea-Taylor, J., Hill, R., \& Kleinhenz, N. (2016). Collaboration and change in the research networks of five Energy Frontier Research Centers. Research Evaluation, 25(4), 472-485. https://doi.org/10.1093/reseval/rvw006.

Tekingunduz, A. (2018). How oil prices impact Russia's economy. Retrieved June 2, 2019, from https:// www.trtworld.com/europe/how-oil-prices-impact-russia-s-economy-22067

Turko, T., Bakhturin, G., Bagan, V., Poloskov, S., \& Gudym, D. (2016). Influence of the program "5-top 100 " on the publication activity of Russian universities. Scientometrics, 109, 769-782. https://doi. org/10.1007/s11192-016-2060-9.

Wang, Z., Porter, A., Kwon, S., Youtie, J., \& Shapira, P. (2019). Updating a search strategy to track emerging nanotechnologies. Journal of Nanoparticle Research, 21, 199. https://doi.org/10.1007/s1105 $1-019-4627-x$

\section{Affiliations}

\section{Valentina Markusova ${ }^{1} \cdot$ Levan Mindeli $^{2} \cdot$ Alexander Libkind $^{1} \cdot$ Anna Zolotova ${ }^{1}$. Mark Akoev ${ }^{3}$}

Valentina Markusova

valentina.markusova@gmail.com

Levan Mindeli

L.Mindeli@issras.ru

Alexander Libkind

anliberty@mail.ru 
Mark Akoev

m.a.akoev@urfu.ru

1 All Russian Institute for Scientific and Technical Information (VINITI) of the Russian Academy of Sciences (RAS), Ulitsa Usievicha 20, Moscow, Russia 125190

2 The Institute for the Study of Science of the Russian Academy of Sciences, Nakhimosvsky Prospekt 32, Moscow, Russia 117485

3 The Ural Federal University, Ekaterinburg, Russia 